International Journal of Wireless \& Mobile Networks (IJWMN) Vol. 3, No. 4, August 2011

\title{
A FAIR COMPARISON BETWEEN HYBRID AND CONVENTIONAL BEAMFORMING RECEIVERS WITH Moderate VAlues of SySTem PARAMETERS
}

\author{
Rim Haddad ${ }^{1}$, Ridha Bouallègue ${ }^{2}$ \\ Laboratory Research in Telecommunication 6'Tel in High School of Communication of \\ Tunis, Route de Raoued Km 3.5, 2083 Ariana, Tunisia \\ 1 rim.haddadeyahoo.ca \\ ${ }^{2}$ ridha.boualleguedsupcom.rnu.tn
}

\begin{abstract}
The main role of smart antennasis to mitigate Multiple Access Interference (MAI) by beamforming (Spatial filtering) operation. In addition to MAI, the performance of receivers is limited by fast fading. In this context, we propose in this paper a hybrid scheme of beamforming and diversity called HBF (Hierarchical Beamforming) and we propose a system model for the mathematical characterization of $H B F$ for the performance evaluation.Moreover, we compare the performance of $H B F$ receiver with conventional Beamforming $(\mathrm{CBF})$ one. The proposed model conforms the benefits of adaptive antennas in reducing the overall interference level (intercell/intracell) and to find an accurate approximation of the error probability.
\end{abstract}

\section{KEYWORDS}

Beamforming, Hierarchical Beamforming (HBF), Conventional Beamforming (CBF), BER, Rayleigh fading

\section{INTRODUCTION}

As the growing demand for mobile communications is constantly increasing, the need for better coverage, improved capacity and higher transmission quality rises. Thus, a more efficient use of the radio spectrum is required. Smart antenna systems have emerged as one of the most efficiency and improving the performance of present and future wireless communication systems.

Several smart antenna systems have been proposed and demonstrated at the base station (BS) of the wireless communication system, and these have shown that significant increases in capacity are possible.

The deployment of smart antennas at cellular base station installations has gained enormous interest because it has the potential to increase cellular system capacity, extend radio coverage, and improve quality of services [1,2].

In a typical mobile environment, signals from users arrive at different angles to the base station and hence antenna arrays can be used to an advantage. Each multipath of a user may arrive at a different angle, and this angle spread can be exploited using an antenna array [3].

The Bit Error Rate (BER) is considered to be one of the most important performance measures for communication systems and hence it has been extensively studied.

In our paper, we propose a novel approach to evaluate the average probability of error by considering an approximation of the spatial filter. Hence, we will derive an analytical model for 
International Journal of Wireless \& Mobile Networks (IJWMN) Vol. 3, No. 4, August 2011

evaluating the mean BER of two smart antenna receivers: the HBF (Hierarchical Beamforming) receiver and the $\mathrm{CBF}$ (Conventional Beamforming) receiver.

The analysis is performed assuming Rayleigh fading multipath environments. We assume to make a comparison between $\mathrm{HBF}$ and $\mathrm{CBF}$ receivers.

We organize the rest of the paper as follows: In section 2, we introduce the system model, followed by the receiver model in section 3 . The general simulation assumptions and simulation results are provided in section 4 and section 5 respectively. We conclude in section 6.

\section{SYSTEM MODEL}

\subsection{System Modelof Hierarchical Beamforming:}

We consider a BS serving a single $120^{\circ}$ angular sector. It is assumed that the BS is equipped with $\mathrm{F}$ co-linear sub-beamforming arrays. The number of array elements in each sub-array is B. That's why the total number of array elements is $M=F \times B$. The inter-element spacing in each sub-array is $d=\lambda / 2$, while the spacing between the adjacent sub-beamforming arrays $\left(d_{S}\right)$, is assumed large enough $\left(d_{S}=20 \lambda\right.$ or more) to uncorrelated fading. The extreme case of $F=1$ and $B=M$ corresponds to the conventional Beamforming.

As the required spacing between sub-arrays for space diversity is much smaller than the sector radius, this AoA is assumed to be the same at each sub-array [4].

We consider $K$ the total number of active Mobile Stations (MS) in the system, which are randomly distributed in the azimuthal direction, along the arc boundary of the sector cell in the far field of the array. Let's assume that $k=1$ be the user of interest.

In this section, we consider that the BS is equipped with a hierarchical Beamforming receiver. Each sub array employs the functional block diagram of OQPSK receiver model.

\subsubsection{Transmitted Signal:}

We assume that the MS transmitter of each user employs offset Quadrature Phase Shift Keying (OQPSK) M-ary orthogonal modulation.

The transmitted signal $s_{k}$ of the $k^{t h}$ user can be written as [5]:

$$
\begin{gathered}
s_{k}(t)=W_{k}^{(q)}(t) a_{k}(t) a^{(I)}(t) \cos \left(w \omega_{c} t\right)+W_{k}^{(q)}\left(t-T_{0}\right) a_{k}\left(t-T_{0}\right) a^{(Q)}(t \\
\left.-T_{0}\right) \sin \left(\omega_{c} t\right)
\end{gathered}
$$

where $W_{k}^{(q)}$ is a Hadamard-Walsh function of dimension $Q$ which represents the $q^{\text {th }}$ orthogonal signal $(q=1,2, \ldots, Q=64)$ of the $k^{t h}$ user, $a^{(I)}$ and $a^{(Q)}$ are the in-phase and quadrature phase pseudo-Noise (PN) sequences, $a_{k}(t)$ is the $k^{t h}$ user long code sequence, $T_{0}$ is the half chip delay for OQPSK signals, $\omega_{c}=2 \pi f_{c}$ and $f_{c}$ is the carrier frequency.

\subsubsection{Channel Model:}

We assume in the following sections that the transmitter signal propagates over Rayleigh fading multipath channel.

The complex equivalent representation of the channel impulse response between the $l^{\text {th }}$ multipath of the the $k^{t h}$ user and the the $b^{t h}$ antenna in the $f^{t h}$ sub-array is given as: 


$$
\tilde{h}_{k, l, b}^{(f)}(t)=\beta_{k, l}^{(f)} e^{-j \varphi_{k, l, b}^{(f)}} \delta\left(t-\bar{\tau}_{k, l}\right)
$$

Where $\beta_{k, l}^{(f)}$ is the path amplitude, $\varphi_{k, l, b}^{(f)}$ is the overall path phase and $\bar{\tau}_{k, l}$ is the path delay respectively. To simplify our work, we assume that multipath channel parameters $\beta_{k, l}^{(f)}$ and $\varphi_{k, l, b}^{(f)}$ remain constant in the duration of Walsh symbol. In vector notation, the spatial signature or channel response vector $h_{k, l}^{(f)}(t)$ is given by:

$$
h_{k, l}^{(f)}=\left[\begin{array}{lll}
h_{k, l, 1}^{(f)} & h_{k, l, 2}^{(f)} & \ldots
\end{array} h_{k, l, B}^{(f)}\right]^{T}
$$

\subsubsection{The received signal:}

At the receiver, the total received signal for the $f^{t h}$ sub-array can be written in vector notation as:

$$
r^{(f)}(t)=\sum_{k=1}^{K} \sum_{l=1}^{L} s_{k}\left(t-\tau_{k, l}\right) h_{k, l}^{(f)}(t)+\eta^{(f)}(t)
$$

where $\tau_{k, l}=\Gamma_{k}+\bar{\tau}_{k, l}, \Gamma_{k}$ is the random delay of the $k^{t h}$ user due to the effect of asynchronous transmission, $\eta^{(f)}$ is the noise which is assumed to be Additive White Gaussian Noise (AWGN) and $h_{k, l}^{(f)}(t)$ the channel response vector given in (2.1.2).

\subsection{System Model of Conventional Beamforming:}

The choice of the second model is based on the reverse link (mobile to base station) of the $3 \mathrm{G}$ CDMA 2000 Systems. We consider K the total number of active Mobile Stations (MS) in the system, which are randomly distributed in the azimuthal direction, along the arc boundary of the sector cell in the far field of the array. For simplicity, the conventional encoder and interleaver are ignored (this approach is widely used [1] for wireless communication systems employing multiple antennas).

\subsubsection{Transmitted Signal:}

The transmitted signal $s_{k}$ of the $k^{t h}$ user can be written as [3]:

$$
s_{k}(t)=W_{k}^{(q)}(t) a_{k}^{(I)}(t) \cos \left(\omega_{c} t\right)+W_{k}^{(q)}\left(t-T_{0}\right) a_{k}^{(Q)}\left(t-T_{0}\right) \sin \left(\omega_{c} t\right)
$$

Where $q=1,2, \ldots, Q, W_{k}^{(q)}(t)$ is a Hadamard-Walsh function of dimension Q which represents the $q^{\text {th }}$ orthogonal signal of the $k^{\text {th }}$ user's long code sequence, $a_{k}(t)$ is the $k^{\text {th }}$ user's long code sequence, $a_{k}^{(I)}(t)$ and $a_{k}^{(Q)}(t)$ are the in-phase and quadrature phase pseudo-noise (PN) sequences, $T_{0}=T / 2$ is the delay for OQPSK signals.

The power of each user is assumed unity (perfect power control). To simplify our study the PN codes are presented as follows: 


$$
\begin{aligned}
& a_{k}^{(I)}(t)=\sum_{r} a_{k, r}^{(I)}(t) p\left(t-T_{C}\right) \\
& a_{k}^{(Q)}(t)=\sum_{r} a_{k, r}^{(Q)}(t) p\left(t-T_{C}\right)
\end{aligned}
$$

Where $a_{k, r}^{(I)}$ and $a_{k, r}^{(Q)}$ are i.i.d variables taking the values \pm 1 with equal probability and $p(t)$ is the chip pulse shape which is assumed to be rectangular.

The equation (5) can be written as follows:

$$
\begin{gathered}
s_{k}(t)=\mathcal{R}\left\{\left[W_{k}^{(q)}(t) a_{k}^{(I)}(t)+j W_{k}^{(q)}\left(t-T_{0}\right) a_{k}^{(Q)}\left(t-T_{0}\right)\right] e^{-j \omega_{c} t}\right\} \\
s_{k}(t)=\mathcal{R}\left\{\widetilde{s_{k}}(t) e^{-j \omega_{c} t}\right\}
\end{gathered}
$$

Where $\widetilde{S_{k}}(t)=S_{k}^{(I)}(t)+j S_{k}^{(Q)}(t)$ is the complex low pass equivalent of the transmitted signal.

\subsubsection{Channel Model:}

The $k^{\text {th }}$ user propagates through a multipath channel with (AoA) $\theta_{k}$. We use the channel model presented in chapter 3 . The complex equivalent representation of the channel impulse response between the $l^{\text {th }}$ multipath of the $k^{\text {th }}$ user and the $n^{\text {th }}$ element of array antenna is presented as follows:

$$
\begin{gathered}
\tilde{h}_{k, l, n}(t)=\beta_{k, l} e^{-j\left(\Phi_{k, l}+2 \pi \frac{d}{\lambda}(n-1) \sin \theta_{k}\right)} \delta\left(t-\bar{\tau}_{k, l}\right) \\
\tilde{h}_{k, l, n}(t)=\beta_{k, l} e^{-j \varphi_{k, l, n}} \delta\left(t-\bar{\tau}_{k, l}\right)
\end{gathered}
$$

where $\beta_{k, l}, \Phi_{k, l}$ and $\bar{\tau}_{k, l}$ are the path gain, phase and delay respectively, $\varphi_{k, l, n}$ is the overall phase which includes the path phase and the difference in propagation delays between the antennas. In this case of transmitter we assume that path gains follow the Rayleigh and Ricean distributions respectively.

To simplify our work, we assume that multipath channel parameters $\beta_{k, l}(t)$ and $\varphi_{k, l, n}(t)$ remain constant in the duration of Walsh symbol [6], so $\beta_{k, l}(t)=\beta_{k, l}$ and $\varphi_{k, l, n}(t)=\varphi_{k, l, n}$ for $t \in\left[0, T_{W}\right]$, where $T_{W}$ is the Walsh symbol period.

\subsubsection{Received Signal:}

At the receiver, the received signal at the $n^{\text {th }}$ antenna element can be written as: 
International Journal of Wireless \& Mobile Networks (IJWMN) Vol. 3, No. 4, August 2011

$$
\begin{aligned}
r_{n}(t)=\sum_{k=1}^{K} \sum_{l=1}^{L} \mathcal{R}\left\{\left[\tilde{s}_{k}\left(t-\Gamma_{k}\right) * \tilde{h}_{k, l, n}(t)\right] e^{-j \omega_{c} t}\right\}+\eta(t) \\
r_{n}(t)=\sum_{k=1}^{K} \sum_{l=1}^{L}\left[\beta_{k, l} W_{k}^{(q)}\left(t-\tau_{k, l}\right) a_{k}^{(I)}\left(t-\tau_{k, l}\right) \cos \left(\omega_{c} t+\varphi_{k, l, n}\right)\right. \\
\left.+\beta_{k, l} W_{k}^{(q)}\left(t-T_{0}-\tau_{k, l}\right) a_{k}^{(Q)}\left(t-T_{0}-\tau_{k, l}\right) \sin \left(\omega_{c} t+\varphi_{k, l, n}\right)\right] \\
+\eta(t)
\end{aligned}
$$

where $\tau_{k, l}=\Gamma_{k}+\bar{\tau}_{k, l}$, and $\Gamma_{k}$ is the random delay of the $k^{t h}$ user due to the effect of asynchronous transmission.

\section{RECEIVER MODEL:}

\subsection{The HBF Receiver Model:}

The HBF receiver is divided in four main blocks which can be identified as follows: (1) the subarray antenna blocks (2) the PN dispreading, (3) the Beamforming and (4) Walsh correlation and demodulation. Figure 1shows the functional block diagram of the HBF receiver.

The received signal at each sub-array antenna is first down converted. Each resolvable path is then detected by one of the RAKE fingers. To detect the $1^{\text {th }}$ path, the signal at the different sensors is dispread using the sequence of the respective mobile and synchronized to the delay of the $\mathrm{l}^{\text {th }}$ path. The post $\mathrm{PN}$-despread signal vector is:

$$
\mathrm{Y}_{\mathrm{k}, \mathrm{l}}^{(\mathrm{f})}=\left[\begin{array}{llll}
\mathrm{y}_{\mathrm{k}, \mathrm{l}, 1}^{(\mathrm{f})} & \mathrm{y}_{\mathrm{k}, \mathrm{l}, 2}^{(\mathrm{f})} & \ldots & \mathrm{y}_{\mathrm{k}, \mathrm{l}, \mathrm{B}}^{(\mathrm{f})}
\end{array}\right]^{\mathrm{T}}
$$

In the next step, the signal after PN dispreading is combined by the Beamforming process. The Beamforming output is given by:

$$
\mathrm{z}_{\mathrm{k}, \mathrm{l}}^{(\mathrm{f})}(\mathrm{t})=\left(\mathrm{W}_{\mathrm{k}, \mathrm{l}}^{(\mathrm{f})}\right)^{\mathrm{H}} \mathrm{Y}_{\mathrm{k}, \mathrm{l}}^{(\mathrm{f})}
$$

Where $\mathrm{W}_{\mathrm{k}, \mathrm{l}}^{(\mathrm{f})}$ is the Maximum SNR Beamforming weight vector given by:

$$
\mathrm{W}_{\mathrm{k}, \mathrm{l}}^{(\mathrm{f})}=\left[\begin{array}{llll}
\mathrm{W}_{\mathrm{k}, \mathrm{l}, 1}^{(\mathrm{f})} & \mathrm{W}_{\mathrm{k}, \mathrm{l}, 2}^{(\mathrm{f})} & \ldots & \mathrm{W}_{\mathrm{k}, \mathrm{l}, \mathrm{B}}^{(\mathrm{f})}
\end{array}\right]^{\mathrm{T}}
$$

To simplify our work, we assume that the weights are set equal to the channel response vector for the desired user. This provides a lower bound on the system performance.

The last step is the correlation of the beamformers with stored replicas of the Walsh functions and then the overall decision variable is obtained by Equal Gain Combining (EGC) of all the decision variables from the multipath signals for the $\mathrm{f}^{\text {th }}$ sub-array. The overall decision is then made by selecting the decision outcomes from the respective sub-beamforming array with the best channel state [4]. 


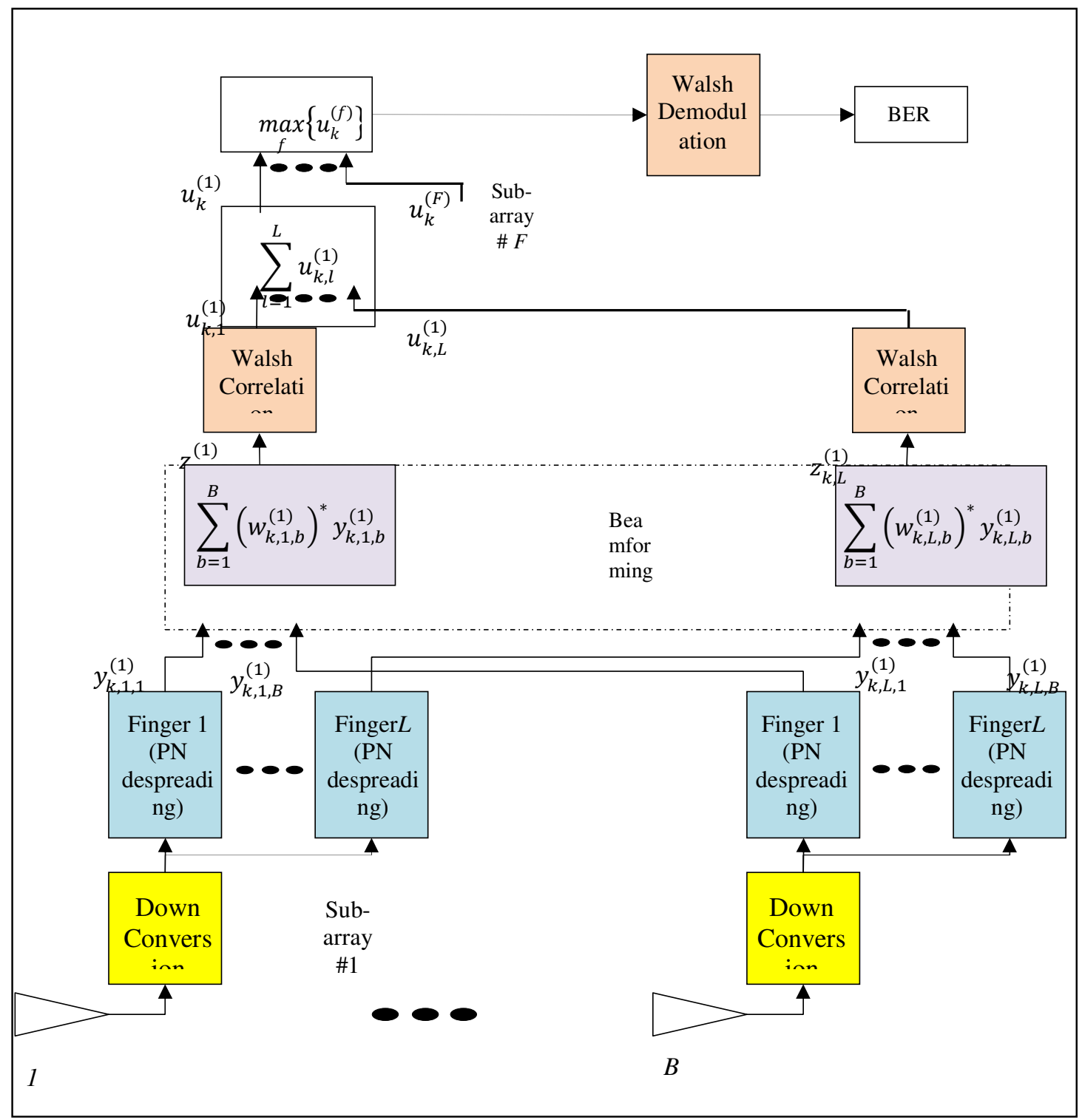

Figure 1: Receiver block diagram for Hierarchical Beamforming

\subsection{The CBF Receiver Model:}

The receiver is divided in four main blocks which can be identified as follows: (1) the array antenna block, (2) the PN despreading, (3) the Beamforming and (4) Walsh correlation and demodulation. We will explain the function of each block:

The first step of the receiver is to obtain the quadrature components at each antenna. We multiply the received waveforms by $\cos \left(\omega_{c} t\right)$ and $\sin \left(\omega_{c} t\right)$ respectively and then Low Pass Filtering (LPF) to remove the double frequency components that results from multiplication [7]. The output of the I-channel and Q-channel low pass filter is given by:

$r_{k, l, n}^{(I)}(t)=\left[r_{k, l, n}(t) \cos \left(\omega_{c} t\right)\right]_{L P F}$ 


$$
\begin{aligned}
&=\left\{\beta_{\mathrm{k}, \mathrm{l}} \mathrm{W}_{\mathrm{k}}^{(\mathrm{q})}\left(\mathrm{t}-\tau_{\mathrm{k}, \mathrm{l}}\right) \mathrm{a}_{\mathrm{k}}^{(\mathrm{I})}\left(\mathrm{t}-\tau_{\mathrm{k}, \mathrm{l}}\right) \frac{\cos \varphi_{\mathrm{k}, \mathrm{l}, \mathrm{n}}}{2}\right. \\
&\left.+\beta_{\mathrm{k}, \mathrm{l}} \mathrm{W}_{\mathrm{k}}^{(\mathrm{q})}\left(\mathrm{t}-\mathrm{T}_{0}-\tau_{\mathrm{k}, \mathrm{l}}\right) \mathrm{a}_{\mathrm{k}}^{(\mathrm{Q})}\left(\mathrm{t}-\mathrm{T}_{0}-\tau_{\mathrm{k}, \mathrm{l}}\right) \frac{\sin \varphi_{\mathrm{k}, \mathrm{l}, \mathrm{n}}}{2}\right\} \\
&+\eta^{(\mathrm{I})}(\mathrm{t}) \\
& \mathrm{r}_{\mathrm{k}, \mathrm{l}, \mathrm{n}}^{(\mathrm{Q})}(\mathrm{t})=\left[\mathrm{r}_{\mathrm{k}, \mathrm{l}, \mathrm{n}}(\mathrm{t}) \sin \left(\omega_{\mathrm{c}} \mathrm{t}\right)\right]_{\mathrm{LPF}} \\
&=\left\{\beta_{\mathrm{k}, \mathrm{l}} \mathrm{W}_{\mathrm{k}}^{(\mathrm{q})}\left(\mathrm{t}-\tau_{\mathrm{k}, \mathrm{l}}\right) \mathrm{a}_{\mathrm{k}}^{(\mathrm{Q})}\left(\mathrm{t}-\mathrm{T}_{0}-\tau_{\mathrm{k}, \mathrm{l}}\right) \frac{\cos \varphi_{\mathrm{k}, \mathrm{l}, \mathrm{n}}}{2}\right. \\
&\left.\quad-\beta_{\mathrm{k}, \mathrm{l}} \mathrm{W}_{\mathrm{k}}^{(\mathrm{q})}\left(\mathrm{t}-\mathrm{T}_{0}-\tau_{\mathrm{k}, \mathrm{l}}\right) \mathrm{a}_{\mathrm{k}}^{(\mathrm{I})}\left(\mathrm{t}-\tau_{\mathrm{k}, \mathrm{l}}\right) \frac{\left.\sin \varphi_{\mathrm{k}, \mathrm{l}, \mathrm{n}}\right\}}{2}\right\} \\
&+\eta^{(\mathrm{Q})}(\mathrm{t})
\end{aligned}
$$

The complex low pass of the received signal can be written as:

$$
\tilde{r}_{k, l, n}(t)=r_{k, l, n}^{(I)}(t)+j r_{k, l, n}^{(Q)}(t)
$$

After filtering, each path is detected by one of the fingers immediately following the radiofrequency stages.

The complex low pass equivalent of the post PN-despread signal is given as $y k, l, n(t)$ :

$y k, l, n t=y_{k, l, n}^{(I)}(t)+j y_{k, l, n}^{(Q)}(t)$

The despreading sequences are denoted as [8]: $\tilde{a}(\mathrm{t})=\mathrm{a}_{\mathrm{k}}^{(\mathrm{I})}\left(\mathrm{t}-\tau_{\mathrm{k}, \mathrm{l}}\right)+\mathrm{ja} \mathrm{k}_{\mathrm{Q}}^{(\mathrm{Q})}\left(\mathrm{t}-\mathrm{T}_{0}-\tau_{\mathrm{k}, \mathrm{l}}\right)$

We can also write as follows:

$$
\begin{aligned}
& \mathrm{y}_{\mathrm{k}, \mathrm{l}, \mathrm{n}}^{(\mathrm{l})}(\mathrm{t})=\mathcal{R}\left\{\left(\tilde{\mathrm{a}}(\mathrm{t}), \tilde{\mathrm{r}}_{\mathrm{k}, \mathrm{l}, \mathrm{n}}(\mathrm{t})\right)\right\}=\mathrm{r}_{\mathrm{k}, \mathrm{l}, \mathrm{n}}^{(\mathrm{I})}(\mathrm{t}) \mathrm{a}_{\mathrm{k}}^{(\mathrm{I})}\left(\mathrm{t}-\tau_{\mathrm{k}, \mathrm{l}}\right)+\mathrm{r}_{\mathrm{k}, \mathrm{l}, \mathrm{n}}^{(\mathrm{Q})}(\mathrm{t}) \mathrm{a}_{\mathrm{k}}^{(\mathrm{Q})}\left(\mathrm{t}-\mathrm{T}_{0}-\tau_{\mathrm{k}, \mathrm{l}}\right) \\
& \mathrm{y}_{\mathrm{k}, \mathrm{l}, \mathrm{n}}^{(\mathrm{Q})}(\mathrm{t})=\mathcal{J}\left\{\left(\tilde{\mathrm{a}}(\mathrm{t}), \tilde{\mathrm{r}}_{\mathrm{k}, \mathrm{l}, \mathrm{n}}(\mathrm{t})\right)\right\}=\mathrm{r}_{\mathrm{k}, \mathrm{l}, \mathrm{n}}^{(\mathrm{I})}(\mathrm{t}) \mathrm{a}_{\mathrm{k}}^{(\mathrm{Q})}\left(\mathrm{t}-\mathrm{T}_{0}-\tau_{\mathrm{k}, \mathrm{l}}\right)-\mathrm{r}_{\mathrm{k}, \mathrm{l}, \mathrm{n}}^{(\mathrm{Q})}(\mathrm{t}) \mathrm{a}_{\mathrm{k}}^{(\mathrm{I})}\left(\mathrm{t}-\tau_{\mathrm{k}, \mathrm{l}}\right)
\end{aligned}
$$

Where $(a, b)=a \cdot b^{*}$ the product between complex numbers. $\tilde{y}_{k, l, n}$ can be written in vector notation as:

$$
\mathrm{Y}_{\mathrm{k}, \mathrm{l}}=\left[\mathrm{y}_{\mathrm{k}, \mathrm{l}, 1}, \mathrm{y}_{\mathrm{k}, \mathrm{l}, 2}, \ldots, \mathrm{y}_{\mathrm{k}, \mathrm{l}, \mathrm{M}}\right]^{\mathrm{T}}
$$

In the next step, the signal after PN despreading is combined by the beamformer. In the Beamforming operation, the signals received by antenna elements are weighted by complex weights and then summed up.

The smart antenna output is given by:

$$
\begin{gathered}
\mathrm{Z}_{\mathrm{k}, \mathrm{l}}=\left(\mathrm{W}_{\mathrm{k}, \mathrm{l}}\right)^{\mathrm{H}} \mathrm{Y}_{\mathrm{k}, \mathrm{l}} \\
\tilde{\mathrm{Z}}_{\mathrm{k}, \mathrm{l}}(\mathrm{t})=\mathrm{Z}_{\mathrm{k}, \mathrm{l}}^{(\mathrm{I})}(\mathrm{t})+\mathrm{j} \mathrm{Z}_{\mathrm{k}, \mathrm{l}}^{(\mathrm{Q})}(\mathrm{t})
\end{gathered}
$$

Where $\mathrm{W}_{\mathrm{k}, \mathrm{l}}$ is the Beamforming weight vector given by:

$$
\mathrm{W}_{\mathrm{k}, \mathrm{l}}=\left[\mathrm{W}_{\mathrm{k}, \mathrm{l}, 1}, \mathrm{~W}_{\mathrm{k}, \mathrm{l}, 2}, \ldots, \mathrm{W}_{\mathrm{k}, \mathrm{l}, \mathrm{M}}\right]^{\mathrm{T}}
$$

To simplify our work, we assume that the weights are set as $\mathrm{W}_{\mathrm{k}, \mathrm{l}}=\mathrm{h}_{\mathrm{k}, \mathrm{l}}$ and these vector channel coefficients are assumed to be perfectly known. This provides the best case system performance.The last step is the correlation of the smart antenna output with stored replicas of the Walsh functions to form the decision variable for demodulation.

The output of the $\mathrm{q}^{\text {th }}$ Walsh correlator $(\mathrm{q}=1,2, \ldots, \mathrm{Q})$ for single antenna is: 


$$
\begin{aligned}
& \mathrm{Z}_{\mathrm{k}, \mathrm{l}}^{(\mathrm{I})}(\mathrm{q})=\frac{1}{\mathrm{~T}_{\mathrm{W}}} \int_{\tau_{\mathrm{k}, 1}}^{\mathrm{T}_{\mathrm{W}}+\tau_{\mathrm{k}, \mathrm{l}}}\left[\mathrm{Z}_{\mathrm{k}, \mathrm{l}}^{(\mathrm{I})} \mathrm{W}^{(\mathrm{q})}\left(\mathrm{t}-\tau_{\mathrm{k}, \mathrm{l}}\right)+\mathrm{Z}_{\mathrm{k}, \mathrm{l}}^{(\mathrm{I})} \mathrm{W}^{(\mathrm{q})}\left(\mathrm{t}-\mathrm{T}_{0}-\tau_{\mathrm{k}, \mathrm{l}}\right)\right] \mathrm{dt} \\
& \mathrm{Z}_{\mathrm{k}, \mathrm{l}}^{(\mathrm{Q})}(\mathrm{q})=\frac{1}{\mathrm{~T}_{\mathrm{W}}} \int_{\tau_{\mathrm{k}, \mathrm{l}}}^{\mathrm{T}_{\mathrm{W}}+\tau_{\mathrm{k}, \mathrm{l}}}\left[\mathrm{Z}_{\mathrm{k}, \mathrm{l}}^{(\mathrm{Q})} \mathrm{W}^{(\mathrm{q})}\left(\mathrm{t}-\tau_{\mathrm{k}, \mathrm{l}}\right)+\mathrm{Z}_{\mathrm{k}, \mathrm{l}}^{(\mathrm{Q})} \mathrm{W}^{(\mathrm{q})}\left(\mathrm{t}-\mathrm{T}_{0}-\tau_{\mathrm{k}, \mathrm{l}}\right)\right] \mathrm{dt}
\end{aligned}
$$

The decision variable for the $\mathrm{l}^{\text {th }}$ multipath of the $\mathrm{k}^{\text {th }}$ user is obtained from the previous values:

$$
\mathrm{u}_{\mathrm{k}, \mathrm{l}}(\mathrm{q})=\left(\mathrm{Z}_{\mathrm{k}, \mathrm{l}}^{(\mathrm{I})}\right)^{2}+\left(\mathrm{z}_{\mathrm{k}, \mathrm{l}}^{(\mathrm{Q})}\right)^{2}
$$

The overall decision variable is obtained by Equal Gain Combining (EGC) of all the decision variables from the $\mathbf{L}$ multipaths as [9]:

$$
\mathrm{u}_{\mathrm{k}}(\mathrm{q})=\sum_{\mathrm{l}=1}^{\mathrm{L}} \mathrm{u}_{\mathrm{k}, \mathrm{l}}(\mathrm{q})=\sum_{\mathrm{l}=1}^{\mathrm{L}}\left[\left(\mathrm{Z}_{\mathrm{k}, \mathrm{l}}^{(\mathrm{I})}\right)^{2}+\left(\mathrm{z}_{\mathrm{k}, \mathrm{l}}^{(\mathrm{Q})}\right)^{2}\right]
$$

Finally, the receiver makes a hard decision on the $\mathrm{q}^{\text {th }}$ symbol of the $\mathrm{k}^{\text {th }}$ user by using the Maximum Likelihood Criteria rule as:

$$
\hat{\mathrm{q}}=\arg _{\mathrm{q}=1, \ldots, \mathrm{Q}} \max \left\{\mathrm{u}_{\mathrm{k}}(\mathrm{q})\right\}
$$

\section{General Simulation AsSumptions}

The performance of HBF array antenna systems is evaluated by means of Montecarlo simulations runs over the variable of interest $\left(E_{b} / N_{0}\right.$ or M). The figure of merit used in this work is the mean Bit Error Rate (BER). This is the mean BER taken over the set of channel Rayleigh fading parameters.

The performance metric is collected and averaged over $M_{c}=100$ drops. A drop is defined as a simulation run for a given number of MS. During a drop, the MS's AoA increases or decreases linearly with angle change $\Delta \theta$ to crossover the entire sector azimuth range $\left[-60^{\circ}, 60^{\circ}\right]$. During a drop, the channel undergoes fast fading according to the motion of the MS's. To simulate the MS mobility, we assume that the snapshot rate is equal to the Walsh symbol rate and the angle change between snapshots is $\Delta \theta=0,01^{\circ}$ per snapshot (MS travelling at $300 \mathrm{~km} / \mathrm{h}$ at only $100 \mathrm{~m}$ from the BS, this value is widely used in simulations).

For clarity of investigations, the main parameters for HBF simulation assumptions are discussed below:

a) Number of Antenna elements: To make the comparison between HBF and CBF, it is merely assumed that the number of antenna elements $M$ is the same for both cases.

b) Number of HBF branches: We consider in simulations that the BS is equipped with $F=2$ co-linear sub-beamforming arrays. This choice of sub-arrays is motivated by practical array size considerations and is relevant to a BS serving three sectors, each covering $120^{\circ}$ in azimuth.

c) Channel: The channel considered is Rayleigh fading with $\mathrm{L}=1,2$ paths/user respectively.

d) Pdf in AoA: We assume a Gaussian pdf in AoA. The angular distribution of the waves arriving at the BS in azimuth is described by the pdf in AoA.

e) Angle Spread: The values of angle spread used in simulations lie in the range $5^{\circ}-15^{\circ}$ which corresponds to urban macrocellular areas.

\section{Simulation Results:}

The performance of HBF is determined by the interaction of a number of factors. These include: Beamforming gain via closely spaced antenna elements within each sub-array beamforming, 
International Journal of Wireless \& Mobile Networks (IJWMN) Vol. 3, No. 4, August 2011

space diversity gain via widely separated sub-arrays beamforming, additional space diversity gain via angle spread and temporal diversity gain via the multipaths. We present in the following sections the impact of each parameter in the performance of $\mathrm{HBF}$ and we will make a fair comparison between $\mathrm{HBF}$ and CBF.

\subsection{Effect of varying Noise level:}

First of all, we study the performance of HBF and CBF for the case of a single user $(K=1)$. Obviously, there is no MAI for the case of one user. We can notice from Figure 2 that both CBF and HBF for different number of antennas show a considerable improvement in mean BER compared to the conventional receiver (super imposed as reference). Besides, the improvement in mean BER increases with $E_{b} / N_{0}$. It is very clear from the figure that the performance of HBF is superior to CBF, e.g for a BER threshold of $10^{-2}, \mathrm{M}=4$ antennas, and $E_{b} / N_{0}$ of about $5 \mathrm{~dB}$ is required for $\mathrm{CBF}$, but only $2.5 \mathrm{~dB}$ is required for $\mathrm{HBF}$. The performance of $\mathrm{HBF}$ is superior to $\mathrm{CBF}$ due to space diversity gain offered by the widely separated sub-arrays, which is dominant factor (in the absence of MAI) for the case of a single user.

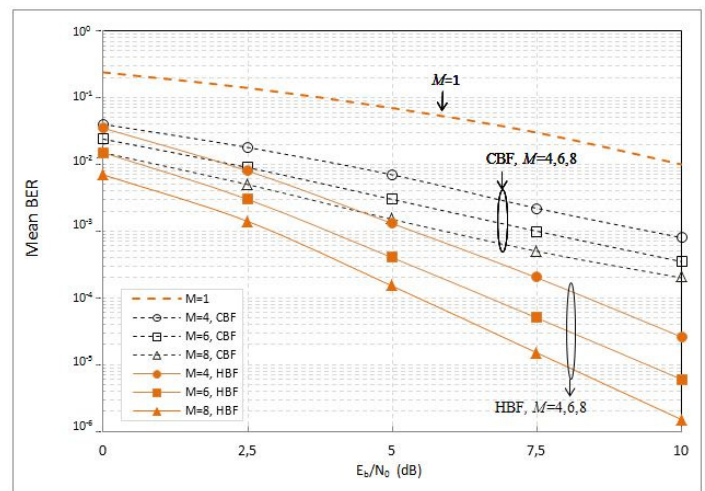

Figure2: Mean BER versus $\mathrm{Eb} / \mathrm{N} 0$ for $\mathrm{K}=1$ user, $\mathrm{L}=2$ paths Rayleigh fading channel, $\sigma \mathrm{AoA}=0^{\circ}$

\subsection{Effect of varying Angle Spread:}

We can notice from Figure 3 that, both $\mathrm{CBF}$ and $\mathrm{HBF}$ improve the performance as the angle spread $\sigma_{A o A}$ increases from $5^{\circ}$ to $10^{\circ}$. It is obvious from the figure, that for low $E_{b} / N_{0}, \mathrm{CBF}$ is slight better than HBF. But, as $E_{b} / N_{0}$ gets higher, diversity gain becomes dominant and HBF becomes better than CBF.

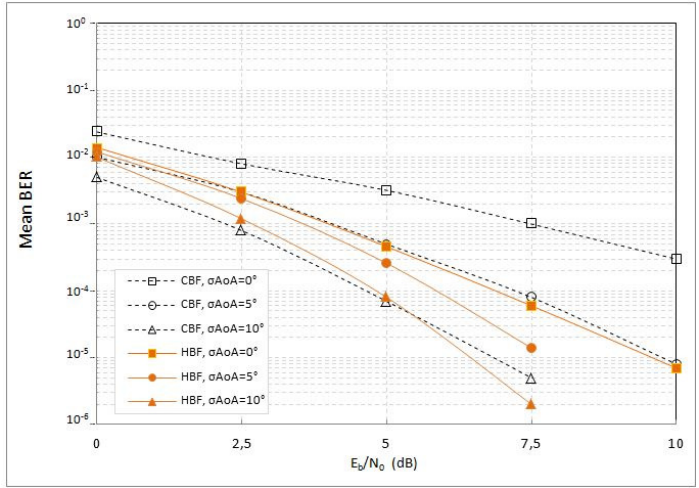

Figure3: Mean BER versus $\mathrm{Eb} / \mathrm{N} 0$ for $\mathrm{K}=1$ user, $\mathrm{L}=2$ paths, $\mathrm{M}=6$ antennas 


\subsection{Effect of varying Number of antennas}

It is noticed from the Figure 4, that for $\sigma_{A o A}=0^{\circ}, \mathrm{HBF}$ is better than $\mathrm{CBF}$ due to diversity gain provided by array architecture. Moreover, there is no much improvement in performance for both $\mathrm{CBF}$ and $\mathrm{HBF}$, by doubling the number of antennas from 4 to 8 . If we want to compare angle spread scenarios, for $\sigma_{A o A}=5^{\circ}, \mathrm{HBF}$ is better than $\mathrm{CBF}$, but for larger angle spreads for $\sigma_{A o A}=10^{\circ}$ and $15^{\circ}$, both array architectures show a similar performance for the number of users considered in simulations.

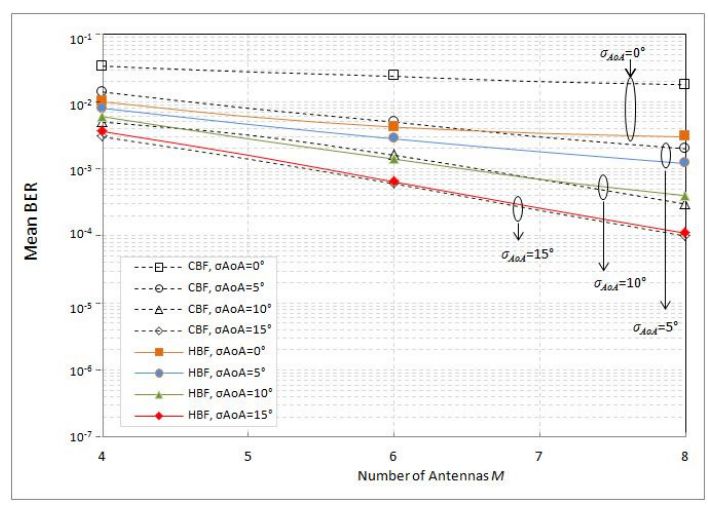

Figure4: Mean BER versus number of antennas $\mathrm{M}, \mathrm{K}=15$ users, $\mathrm{L}=1$ path/user

\section{Conclusions:}

In this paper, we have reported on the performance of hybrid scheme of diversity and Beamforming. Furthermore, its performance is compared with conventional Beamforming with moderate values of the system parameters such as angle spread number of antennas, number of multipath and number of users. It has be shown that while assuming zero angle spread, the performance of $\mathrm{HBF}$ is superior to $\mathrm{CBF}$ due to space diversity gain afforded by the well separated sub-arrays. The inclusion of angle spread produces spatial fading across the array, which results in additional diversity gain and improves the performance of both CBF and HBF schemes. For the case of moderate or large angle spread, when path diversity is present and the system is heavily loaded, CBF yields better mean BER results than HBF. All these results are based on the assumption of perfect channel estimation, that's why the choice of optimum receiver architecture is dependent on the channel conditions.

\section{REFERENCES}

[1] S. Bellofiore et al., "Smart antenna system analysis, integration and performance for Mobile Ad-Hoc Networks (MANET's),” IEEE Trans. AntennasPropagat., vol. 50, pp. 571-581, May 2002.

[2] M. Ho, G. Stuber, and M. Austin, "Performance of switched-beam smart antennas for cellular radio systems,” IEEE Trans. Vehic. Technol., vol.47, pp. 10-19, Feb. 1998.

[3] R.Haddad, R.Bouallègue, "BER Performance in Space-Time Processing receiver using Adaptive Antennas over Rayleigh Fading Channels", Proc. IEEE International Conference on signal Processing and Communication , pp.1483-1486 Nov. 2007.

[4] B. A. Bjerke, Z. Zvonar, and J. G. Proakis, "Antenna diversity combining aspects for WCDMA systems in fading multipath channels", IEEE Transactions on Wireless Communications, vol. 3, no. 1, pp. 97-106, Jan. 2004.

[5] MonzigoA.Roberts, Miller Thomas, Introduction to Adaptive Arrays. Sc Tech Publishing, 2004.

[6] R.Haddad, R.Bouallègue, "BER Performance of Smart Antenna Systems Operating over Rayleigh fading Channels", proc. IEEE Wireless Days 2008, pp.1-5, Nov. 2008. 
International Journal of Wireless \& Mobile Networks (IJWMN) Vol. 3, No. 4, August 2011

[7] T. S. Rappaport, Wireless Communications: Principles and Practice, 2nd ed. Prentice Hall, 2002.

[8] G. L. Stuber, Principles of Mobile Communication, 2nd ed. Kluwer Academic Publishers, 2001.

[9] C. D. Iskander and P. T. Mathiopoulos, "Performance of multicode DS/CDMA with M-ary orthogonal modulation in multipath fading channels," IEEE Transactions on Wireless Communications, vol. 3, no.1, pp. 209-223, Jan. 2004.

\section{Authors}

Rim Haddad (M'05) Received the B. Eng. Degrees in Telecommunication from the High School of Telecommunication of Tunis (SUP'COM). From 1997 to December 2006, she was Engineer in Telecommunication in Tunisie Telecom. Since January 2007 she was an university assistant in the High School of Computing, she has taught courses in telecommunications and security computing. She is currently working toward the Ph.D. degree in Telecommunication systems also at the High School of Telecommunication of Tunis in the Laboratory research of System Telecommunication (6'Tel).

She has worked in several areas including smart antennas, space-time receivers, and angular gain.She's current research interests include smart antenna systems, compact antenna design, and propagation characterization for wireless communications.Ms. Rim won the best paper award of the IEEE-ISIE conference in Montreal Canada.

RidhaBouallègue (M'98) received the Ph.D degrees in electronic engineering from the National Engineering School of Tunis. In Mars 2003, he received the Hd.R degrees in multiuser detection in wireless communications. From September 1990 he was a graduate Professor in the higher school of communications of Tunis (SUP'COM), he has taught courses in communications and electronics. From 2005 to 2008, he was the Director of the National engineering school of Sousse. In 2006, he was a member of the national committee of science technology. Since 2005, he was the laboratory research in telecommunication Director'sat SUP'COM

From 2005 he served as a member of the scientific committee of validation of thesis and Hd.R in the higher engineering school of Tunis. His current research interests include wireless and mobile communications, OFDM, space-time processing for wireless systems, multiuser detection, wireless multimedia communications, and CDMA systems. 